\title{
Research on Investment Strategy of Power Grid Company's Distribution Network under the Background of Power System Reform
}

\author{
Yi Song1, Chongbo Sun ${ }^{1}$, Kai Yuan ${ }^{1}$, Hanbin Zhang ${ }^{1}$, Chenjun Sun ${ }^{2}$ \\ ${ }^{1}$ State Grid Economic and Technological Research Institute CO., LTD, Beijing 102209, China; \\ 2State Grid Hebei Electric Power Company, Hebei 050000, China.
}

\begin{abstract}
The distribution network investment is an important business area of power Grid Company. Under the background of power system reform, more participants will participate in the investment business of distribution network. And the power grid will be in face to fierce market competition. This paper introduce an investment strategy of power Grid Company's distribution network, so as to help the power grid companies to solve the problem.
\end{abstract}

Keywords: Distribution network investment; power Grid Company; fierce market competition; investment strategy.

\section{Strategy Recommendations for the Stock Portion}

Relying on the internal and external environment faced by the grid company in the field of distribution network investment planning, there are two possibilities for the comparison between the investment capacity of the grid company's stock distribution network and the investment demand, namely: the investment capacity is greater than the investment demand, and the investment capacity is less than the investment demand [1,2]. The following is a detailed description of the development strategy of the stock distribution network corresponding to the grid companies in these two possible situations.

\subsection{Investment Capacity Is Greater Than Investment Demand - Open Investment Strategy}

The permitted investment scale under the regulation of transmission and distribution price is higher than the investment demand obtained by the investment demand measurement model under the user reliability target [3]. This means that the size of the permitted investment of the grid company under certain regulatory targets for transmission and distribution prices exceeds the level of user reliability during the regulatory period. Under this circumstance, in the future, during the period of certain supervision, the grid companies can adopt an open investment strategy in the field of stock distribution and distribution network, which is mainly reflected in the following two aspects:

(1) Improve user reliability

In the case of investment capacity surplus, grid companies can focus on improving the reliability of power supply for high-sensitivity power users. First, the power users are sorted from high to low according to different reliability of power supply reliability (for example, high-sensitivity user group, second-high sensitive user group, common user group, and low-sensitive user group). According to the size of excess investment, the power supply reliability level of power users is improved moderately, and the investment of the power users with high reliability sensitivity is focused on to further enhance the satisfaction of power users, which will help the Power Grid Corp to strengthen the viscosity of the users in the open market environment and enhance the competitiveness of the electricity sale.

(2) Increase investment in new technologies

With the refinement of the construction network transformation and the increasing proportion of distributed energy, the technical requirements of the distribution network will continue to increase. In the case of investment capacity surplus, the grid company can invest in new technologies such as distribution network automation technology, intelligent line switching technology, power electronics technology, etc., and put these technologies into the daily operation management of the distribution 
network to promote the distribution network system to further intelligence. Upgrade to meet the increasing demand for distributed power, energy storage and other equipment in the future.

\subsection{Investment Capacity Is Less Than Investment Demand - Conservative Investment Strategy}

The permitted investment scale under the regulation of transmission and distribution price is lower than the investment demand obtained by the investment demand measurement model under the user reliability target. This means that the size of the permitted investment of the grid company under certain regulatory standards for transmission and distribution prices cannot be satisfied with the level of user reliability during the regulatory period. Under this circumstance, the grid company can adopt a conservative investment strategy, and the core idea is to moderately reduce the level of power supply reliability [4].

When the investment ability of the grid company is difficult to meet the requirements of the user's power supply reliability level, the power supply reliability level of the local power users can be appropriately reduced according to the difference in reliability sensitivity of the power users. Based on the classification of power users' reliability from high to low, the power supply reliability level of power users is moderately reduced according to the gap of investment scale, mainly reducing the reliability level of power users with lower reliability sensitivity, ensuring that the grid company's profit decline due to insufficient power supply reliability and the potential loss due to the reduction of power user's viscosity in the open electricity market environment are minimized under the limited investment capacity.

\section{Policy Recommendations for the Incremental Section}

In the process of participating in the incremental distribution network investment, the grid company has various problems that hinder the development of the company. In order to ensure the effectiveness and timeliness of the company's participation in incremental investment, this part proposes relevant suggestions for solving the problem [5].

\subsection{Decentralize the Management Authority of the Incremental Power Distribution Business to Improve the Efficiency of Company Decision-Making}

The unified and complete management system of State Grid Corporation guarantees that the provincial power companies conduct daily operation and management based on the same standard. However, for the market-oriented incremental power distribution business, the current investment decision-making process is not applicable. The use of the existing management system is likely to cause the provincial power companies to be limited in the market preemption, investment construction, planning and operation of the incremental placement of electricity business, and cannot make timely and effective response strategies for real-time changing market environment, which is difficult to meet the time requirements for the local government to attract investment and increase the allocation of the network as soon as possible, thus missing market opportunities and the market competition efficiency is low.

\subsection{Improve the Mechanism Guarantee for the Company to Carry Out Incremental Power Distribution Business}

The pace of the expansion of the incremental power distribution business is accelerating, and the company's incremental power distribution business will face fierce market competition, and it needs to support the mechanism of market-oriented operation. First, establish an investment mechanism for incremental distribution network projects, give decision-making authority to provincial power companies, and allow provincial, prefecture-level companies and project stakeholders to form project companies to seek a win-win situation; The second is to optimize the investment decision-making process and material procurement system of the incremental distribution network project, and quickly respond to the service needs of customers in the incremental distribution network area; The third is 
to innovate the remuneration mechanism of employees in the incremental distribution business, adopt market-based incentives, and motivate employees to conduct competitive business, and help the State Grid Corporation to introduce and retain outstanding talents.

\subsection{Optimize Investment Decision-Making Process and Establish A Scientific Investment Planning Lean Management System}

For different business needs, rationally arrange regulatory grid investment and non-regulated incremental power distribution business investment, reduce the pre-decision decision-making process of incremental distribution network projects, establish priority approval mechanism for key projects, and improve the flexibility of operation in the incremental distribution network market, maximize the investment income of the grid company under the premise of ensuring reasonable grid scale and power supply reliability. Through the scientific schedule management system, we ensure that all types of project investment can be implemented on time and effectively, and improve the management level of power grid projects and the effective utilization rate of funds.

\section{References}

[1]. Deepak Kumar, S. R. Samantaray, G. Joos. A reliability assessment based graph theoretical approach for feeder routing in power distribution networks including distributed generations[J]. International Journal of Electrical Power and Energy Systems, 2014, 57.

[2]. A. Bather, H. Monsey, H. Lesani. Integrated distribution network expansion planning incorporating distributed generation considering uncertainties, reliability, and operational conditions[J]. International Journal of Electrical Power and Energy Systems, 2015, 73.

[3]. Mendoza B. Jorge, Vargas O. Hector, Lopez G. Miguel, Paves D. Héctor. Multi-fault service restoration in distribution networks considering the operating mode of distributed generation[J]. Electric Power Systems Research, 2014, 116.

[4]. M. Siddhi, M. Aliabad- Glomar, M.-R. Haghifam. Distribution network expansion considering distributed generation and storage units using modified PSO algorithm[J]. International Journal of Electrical Power and Energy Systems, 2013, 52.

[5]. R. Ibrahim, M. Ahsan, H. Nouri. A profit-centric strategy for distributed generation planning considering time varying voltage dependent load demand[J]. International Journal of Electrical Power and Energy Systems, 2013, 441. 